\title{
Speaker Overestimation of Communication Effectiveness and Fear of Negative Evaluation: Being realistic is unrealistic
}

Nicolas Fay, Andrew C Page, Crystal Serfaty, Vivien Tai \& Christopher Winkler

The University of Western Australia

Running Head: INTERPERSONAL COMMUNICATION

Keywords: Interpersonal Communication, Fear of Negative Evaluation, Social Anxiety, Social Phobia, Self-efficacy

Corresponding author:

Nicolas Fay, School of Psychology, University of Western Australia 35 Stirling Highway, Crawley, WA 6009 Australia

Email:nfay@psy.uwa.edu.au; Tel: +61 (0)8 6488 2688; Fax: +61 (0)8 64881006

Word count (excluding title page, abstract, figure \& tables): 4025 words. 


\begin{abstract}
Speakers systematically overestimate their communication effectiveness (Keysar \& Henly, 2002). We argue that doing so is adaptive, reducing the risk of social anxiety and withdrawal from social situations. This hypothesis was tested by having speakers who score low and high on fear of negative evaluation (FNE), a hallmark of social phobia, attempt to convey a specific meaning of ambiguous statements to a listener and then estimate their communication effectiveness. Low FNE speakers consistently overestimated their effectiveness, expecting the listener to understand their intended meaning more often than they actually did. In contrast, high FNE speakers' estimate of communication effectiveness was consistent with the listener's actual understanding. Signal detection analysis revealed that low and high FNE speakers were equally able to discriminate communication success from failure, but low FNE speakers exhibited a stronger positive response bias. In conclusion, overestimating one's communication effectiveness is adaptive and accurate estimation is associated with dysfunction.
\end{abstract}


Speaker Overestimation of Communication Effectiveness and Fear of Negative

Evaluation: Being realistic is unrealistic

Human communication is central to many everyday activities such as conversing with a loved one, making small talk with a shop assistant or giving a speech, and greater confidence in one's ability to communicate fosters engagement in these pursuits. However, speakers do not always communicate as successfully as they believe they do. In fact, speakers are found to systematically overestimate their communication effectiveness. Keysar and Henly (2002) had speakers communicate one of two possible meanings of ambiguous statements to listeners, such as 'Alan painted the picture in the kitchen'. On average speakers believed they had successfully communicated the intended meaning of the ambiguous statements on $72 \%$ of trials (e.g., the picture hanging in the kitchen was painted by Allan as opposed to the kitchen being the location where Allan painted the picture). By comparison, listeners' average identification rate was $61 \%$, indicating that speakers overestimated their communication success. The discrepancy between perceived and actual performance is explained by a selfefficacy bias known as the 'illusion of transparency', that leads speakers to believe their intentions are more transparent than they really are.

Why might such an illusion exist? It has been argued that an optimistic sense of self-efficacy promotes the perseverant effort needed for personal and social accomplishments (Bandura, 1989). We propose that by leading speakers to believe they are more competent communicators than they are, the illusion of 
transparency may promote social interaction and insulate the speaker against adversity (e.g., looks of bemusement or boredom). Given the importance and pervasiveness of language use, and its inherent ambiguity (Altmann, 1998; Schober \& Conrad, 1997), it is intuitively appealing to consider the illusion of transparency to be adaptive. Indeed, without this illusion individuals would be more cognizant of their communicative inadequacies, increasing self-focused attention, a correlate of social anxiety and anxiety more generally (Clark \& Wells, 1995). The current study tests the hypothesis that people vulnerable to social anxiety will lack this self-efficacy bias.

While everyone experiences social anxiety from time to time (e.g., during a job interview), individuals who suffer from social phobia experience anxiety more intensely than others. Social phobia is an anxiety disorder characterized by a disproportionate fear of social interactional or performance situations (American Psychiatric Association, 2000). According to cognitive-behavioral models (Clark \& Wells, 1995; Rapee \& Heimberg, 1997), social phobia results from an interplay between fear of negative evaluation (FNE) and excessive self-directed attention. In short, socially anxious persons are preoccupied about being negatively evaluated by others and this causes them to become anxious. In turn, heightened anxiety promotes painstaking monitoring of negative behaviors by self (e.g., blushing) and others (e.g., frowning). These behaviors, in addition to an elevated motivation to make a positive impression on others, widen the perceived discrepancy between actual and expected performance, fueling a vicious cycle of anxiety. 
Unlike the milder anxiety experienced by shy persons in social evaluative settings, the intense anxiety experienced by the social phobic person is functionally debilitating, often causing the sufferer to avoid social situations. Consequently, individuals with high levels of social anxiety have fewer friends and romantic relationships when compared with members of the general population (Alden \& Taylor, 2004).

Although there is a general consensus among current conceptual accounts that a negative interpretative bias underpins social anxiety (i.e., a bias to interpret ambiguous social information negatively), research to date is inconclusive. For instance, one questionnaire study found that social phobia patients interpreted ambiguous social information in a more negative manner than nonanxious controls (Amin, Foa, \& Coles, 1998), whereas another found that socially anxious persons lacked the positive interpretative bias seen in a nonanxious control group (Constans, Penn, Ihen, \& Hope, 1999). Importantly, the negative bias, or lack of positive bias seen in these studies was specific to social information. Reaction-time tasks, designed to assess immediate, or on-line processing find that social phobic and socially anxious persons lack the positive interpretative bias observed in nonanxious controls (Hirsch \& Mathews, 1997, 2000).

Mixed results are also found in tasks where individuals interpret their own performance (e.g., giving a speech or conversing with a partner). Several studies show that socially anxious individuals systematically underestimate their social performance relative to observer ratings (Alden \& Wallace, 1995; Rapee \& Lim, 
1992), whereas others find they hold an accurate representation of their social ability (Woody \& Rodriguez, 2000). Thus, relative to an overestimating 'normal' population, it is unclear whether social anxiety is characterized by the lack of a positive interpretative bias (i.e., an accurate perception of reality) or a negative interpretation of performance (see Hirsch \& Clark, 2004 for a review).

By adopting a communication task where speaker performance is objectively measured (i.e., listener comprehension), the current study extends prior research that has relied on subjective ratings of speaking ability. We address the issue of performance bias by having persons scoring low and high on FNE, a hallmark of social phobia, participate in a dyadic communication task where perceived and actual performance is contrasted. Specifically, the study addresses two questions: (1) do high FNE speakers rate their communication effectiveness more negatively than low FNE speakers, and if so (2) do high FNE speakers realistically appraise their speaking ability or underestimate their speaking ability?

\section{Methods}

\section{Participants}

344 undergraduate psychology students were screened using the Fear of Negative Evaluation questionnaire (FNE-q; Watson \& Friend, 1969). The FNE-q consists of 30 Yes/No statements such as, "Sometimes I am too concerned with what people think of me", where a higher score (0-30) indicates greater fear of 
negative evaluation from others. The FNE-q demonstrates high internal consistency $(\alpha=.94)$ and test-retest reliability $(r=.78)$ (Watson \& Friend, 1969).

Of those screened, persons scoring in the lower and upper quartiles were invited to participate in the present study. Twenty-six low and 26 high FNE participants ( 11 and 19 females respectively) were recruited as speakers ( $M_{\mathrm{LOW}}=$ 5.7, $M_{\mathrm{HIGH}}=26.8 ; t(50)=33.64, d=9.37$, where $F$ and $t$ values are significant at $p<.05$ unless otherwise stated). On account of frequent anxiety and depression co-morbidity (Clark \& Watson, 1990), persons in the high FNE group also scored higher on depression (measured using the depression subscale of the DASS; Lovibond \& Lovibond, 1995) than those in the low FNE group $\left(M_{\mathrm{LOW}}=3.9, M_{\mathrm{HIGH}}=\right.$ 9.1; $t\left(43^{1}\right)=2.34, d=.66$ ). All participants were native English speakers and free of any speech or hearing impediment.

\section{Materials and Procedure}

The procedure and materials were identical to those employed by Keysar and Henly (2002), with the exception that we used a single listener to eliminate between-listener variability. The listener was blind to group membership and the speakers' intended meaning.

Speakers were given a booklet containing 16 ambiguous test sentences (one on each page) and their associated disambiguating scenario. Test sentences comprised 12 syntactically ambiguous statements (e.g., 'Allan painted the picture in the kitchen') and 4 lexically ambiguous statements (e.g., 'the bodybuilder had a massive chest'). Applying the appropriate prosodic cues 
could, in principle, disambiguate the syntactically ambiguous statements, but not the lexically ambiguous statements (Allbritton, McKoon, \& Ratcliff, 1996; Price, Ostendorf, Shattuckhufnagel, \& Fong, 1991). Thus, if speakers are sensitive to the comprehensibility of the material communicated, their perceived ability to communicate lexically ambiguous statements will be lower than for syntactically ambiguous statements.

Pre-tests established the dominance of each target statement for an Australian population (e.g., that the body builder's torso comes to mind more readily than his furniture in the previous lexical example). Item dominance was counter-balanced to ensure an average dominance bias of $50 \%$ across test items for each subject. Thus, each speaker attempted to communicate the dominant interpretation of $50 \%$ of test items (randomly ordered) and the non-dominant interpretation on the remainder.

Speaker-listener pairs faced each other from opposite sides of a round table, $1 \mathrm{~m}$ in diameter. Speakers silently read the associated disambiguating scenario, and then verbally conveyed the ambiguous statement. Once the speaker had finished speaking, the listener turned around to prevent the transmission of nonverbal feedback (e.g., looks of encouragement or puzzlement). At this point, the two competing disambiguating scenarios were projected onto the wall facing the listener (Table 1 displays a sample trial). The speaker then indicated which interpretation they believed the listener would understand by circling one of two responses in the test booklet (i.e., the intended or unintended interpretation). The listener indicated which interpretation she 
understood in the same manner. All responses were recorded privately (a small visual barrier prevented participants from observing their partner's response) and no explicit feedback, with regard to communication success or failure, was given. The percentage of trials where the speaker selected his/her intended interpretation represents perceived accuracy, whereas the percentage of trials where the listener identified the speaker's intended interpretation represents actual accuracy.

\section{Results}

\section{Listener Consistency and Accuracy}

To ensure the listener was behaving consistently as she accumulated listening experience, listener accuracy scores (\% of speakers' intended messages the listener understood) were compared across speakers (early, late i.e., the first vs. second $50 \%$ of speakers tested). No statistically significant difference was found $\left(M_{\text {early }}=66.5 \%, M_{\text {late }}=64 \% ; t(51)<1, d=0.16\right)$. In short, the listener behaved consistently across speakers; her accuracy was a function of the speakers' ability to convey the intended message. Notice also that listener accuracy (66\%) was significantly higher than chance $(50 \%)(t(51)=7.52, d=1.07)$. Evidently, speakers could disambiguate the target statements, albeit with modest success.

\section{Speakers' Perceived and Actual Communication}

Low fear of negative evaluation (FNE) speakers tended to overestimate (perceived $>$ actual) their ability to convey the intended message (62\% of cases). 
Few underestimated (perceived < actual) their communicative ability (23\%) and fewer still were realistic (perceived $=$ actual) $(15 \%)$. In contrast, high FNE speakers showed a more even distribution of overestimation (38\%) and underestimation (54\%), with few being accurately calibrated (8\%). The data are plotted in Figure 1, where the diagonal line reflects accurate calibration.

Collapsing performance scores across conditions indicates that low FNE speakers systematically overestimated their communication effectiveness for syntactically ambiguous statements $\left(M_{\text {perceived }}=77 \%, M_{\text {actual }}=67 \%\right)$ and lexically ambiguous statements $\left(M_{\text {perceived }}=69 \%, M_{\text {actual }}=57 \%\right)$. In contrast, high FNE speakers were more accurately calibrated for both syntactically ambiguous statements $\left(M_{\text {perceived }}=63 \%, M_{\text {actual }}=68 \%\right)$ and lexically ambiguous statements $\left(M_{\text {perceived }}=60 \%, M_{\text {actual }}=60 \%\right.$; see Figure 2$)$.

Participants' mean performance scores (\%) were entered into a mixed design ANOVA, treating performance (perceived, actual) and stimuli (syntactic, lexical) as within subject factors and FNE (low, high) as between. This returned no main effect of performance or FNE $\left(F s<2.12, \eta_{p}{ }^{2}<0.04\right)$, but a reliable main effect of stimuli $\left(F(1,50)=8.03, \eta_{\mathbf{p}}{ }^{2}=0.14\right)$. Thus, speakers were better able to communicate the intended meaning of syntactically ambiguous statements to the listener when compared with lexically ambiguous statements. Their lower perceived ability to convey the lexically ambiguous statements suggests they are cognizant of this. The FNE by stimuli interaction and performance by stimuli interaction was non-significant, as was the 3-way FNE by performance by stimuli 
interaction $\left(F_{S}<1, \eta_{\mathbf{p}}{ }^{2}<0.02\right)$. There was however a reliable FNE by performance interaction $\left(F(1,50)=6.55, \eta_{p}{ }^{2}=0.12\right)$. The interaction is explained by low FNE speakers systematically overestimating their performance $(F(1,50)=8.07, d=$ $.63)$, and high FNE speakers not doing so $(F<1, d=.24)$. Notice also that there was no difference in the actual performance of low and high FNE speakers $(F<1$, $d=.06)$.

In summary, relative to an overestimating 'normal' population, high FNE speakers evenhandedly interpreted their performance, evidenced by a perceived speaking ability that reflects actual ability. However, it is unclear if the 'accurate' calibration of high FNE speakers reflects speaker sensitivity or the lack of a positive interpretative bias. In other words, are high FNE speakers more cognizant of their communicative ability on a trial-by-trial basis when compared with low FNE speakers or are they equally error prone, but overestimate less? Knowing whether high FNE speakers differ in terms of sensitivity or response bias (see Macmillan \& Creelman, 1991) provides direction for future treatment interventions (see discussion).

Signal detection analysis places participants' responses into one of four categories: hits, misses, false alarms and correct rejections. In the present study, a hit occurs when the speaker correctly predicts that the listener understood the intended message. Failing to recognize that the listener understood the intended message is a miss. Mistakenly predicting that the listener understood the intended message when she did not is a false alarm. 
And correctly recognizing when the intended message was not understood is a correct rejection.

In the present study sensitivity measures the speaker's ability to distinguish communication success from failure. To determine speaker sensitivity, $d$ ' was calculated for each speaker and entered into an independent samples t-test ${ }^{1}$. While low FNE speakers demonstrated a higher average hit rate $\left(\mathrm{FNE}_{\mathrm{LOW}}=82 \%, \mathrm{FNE}_{\mathrm{HIGH}}=71 \%\right)$, high FNE speakers committed fewer false alarms $\left(\mathrm{FNE}_{\mathrm{LOW}}=63 \%, \mathrm{FNE}_{\mathrm{HIGH}}=55 \%\right)$. The net result was a comparable mean $d$ ' score across groups ( $\left.\mathrm{FNE}_{\mathrm{LOW}}=.54, \mathrm{FNE}_{\mathrm{HIGH}}=.47 ; t<1, d=.09\right)$. Thus, high FNE speakers were not better able to discriminate communication success from failure when compared with low FNE speakers.

Response bias is the tendency to favor one response over another. Given the comparable sensitivity of low and high FNE speakers, it follows that high FNE speakers' accurate calibration may result from less biased responding. In other words, we predict that low FNE speakers may be more biased towards a positive response (i.e., that the listener understood the intended message) than high FNE speakers (i.e., a one-tailed test). Response bias was calculated for each speaker and the results were entered into an independent samples t-test. Low FNE speakers exhibited a stronger response bias than high FNE speakers $\left(F_{N} E_{L O W}=-\right.$ $\left..60, \mathrm{FNE}_{\mathrm{HIGH}}=-.34\right)$ and this difference was significant $\left(t_{\text {one-tailed }}(50)=1.87, d=\right.$ .53). Hence, the accurate calibration observed among high FNE speakers is not

\footnotetext{
${ }^{1}$ Infinite values were avoided by adding a frequency of 0.5 to all data cells before converting to proportion scores (Snodgrass \& Corwin, 1988).
} 
a function of speaker sensitivity; it is a consequence of speaker responding that is less colored by a positive response bias.

\section{Discussion}

The present study investigated the existence of the 'illusion of transparency' within a population vulnerable to social phobia. Given that this self-efficacy bias leads 'normal' speakers to overestimate their communication effectiveness, it was unclear whether high FNE speakers would accurately appraise their speaking ability or underestimate their speaking ability. Our results are consistent with the former explanation.

Echoing prior research, low and high FNE speakers did not differ on actual speaking performance (Alden \& Wallace, 1995; Rapee \& Lim, 1992; Woody \& Rodriguez, 2000). Replicating Keysar and Henly's (2002) findings, low FNE speakers systematically overestimated their communication effectiveness. This applied to both syntactically ambiguous statements that can be disambiguated by applying the appropriate prosodic cues, and lexically ambiguous statements that cannot be disambiguated via prosody alone. Thus, members of the 'normal' population are overestimators. High FNE speakers on the other hand demonstrated no such bias, their perceived and actual ability to communicate the ambiguous statements being closely aligned. Thus, members of this 'abnormal' group could be characterized as pathological realists.

The final analysis clarified the basis of the communicative realism exhibited by high FNE speakers. Signal detection analysis revealed that low and 
high FNE speakers were equally able to discriminate communication success from failure, but low FNE speakers exhibited a stronger positive interpretative bias (i.e., they more frequently responded that the listener understood their intended message, and more often than was merited).

Thus, relative to an overestimating normal population, the negative mental representation of self, central to conceptual models of social phobia (Clark \& Wells, 1995; Rapee \& Heimberg, 1997), was supported. However, the negative illusion they imply was not supported. Rather, social anxiety is conceivably better characterized by the absence of positive illusions. This position is consistent with that of Woody and Rodriguez (2000), and complements Hirsch and Matthews' $(1997,2000)$ finding that socially anxious persons lack the positive interpretative bias seen in nonanxious persons. Lacking a rose-tinted view of their speaking skills, high FNE speakers are more cognizant of their communicative shortcomings, heightening the risk of social anxiety and withdrawal from social situations.

The adaptive value of perceived self-efficacy and its causal role in anxiety and phobic behavior is nicely illustrated by Savitsky and Gilovich (2003). They found that individuals believe their nervousness when delivering a public speech is more apparent to their audience than it actually is. Importantly, informing prospective speakers that their nervousness is less apparent than they think reduced speech anxiety and improved their speaking performance. Thus, increasing perceived self-efficacy reduced anxiety and improved performance (see also Bandura, 1989; Wilson, MacLeod, Mathews, \& Rutherford, 2006). This 
position resonates with research that has assessed the relationship between positive illusions and psychological well-being. Counter to traditional realismbased theories of mental health, Taylor and Brown (1988) review a series of studies that link positive illusions with subjective well-being. Its corollary, consistent with the depressive realism hypothesis (Alloy \& Abramson, 1979), is that the mental health of persons who lack these positive illusions is at risk.

Although any treatment implications must be speculative, our findings suggest that cognitive-behavioral techniques could be improved. To avoid a distorted interpretation of their performance, clients with social anxiety are encouraged to focus on the situation itself, and use external cues (e.g., an interlocutor's smile) to challenge their negative self-appraisals (Clark \& Wells, 1995). Our findings show that people with elevated FNE lack the optimism seen among members of the general population. Treatments might therefore include a positive biasing technique. For example, when uncertain clients would be encouraged to believe their communication was successful. As the signal detection analysis shows, doing so would maintain speaker sensitivity and de facto promote a positive illusion, which may induce future social engagement. Our suggestion is not without precedent in the literature. Initial attempts to facilitate a benign interpretation bias in a socially anxious population are encouraging; participants trained to positively interpret ambiguous social information anticipate being less anxious and believe they will perform better in future social situations (Murphy, Hirsch, Mathews, Smith, \& Clark, 2007). 
It is important to address two potential limitations to the present study: our use of a non-clinical sample and the possible influence of co-occurring depression. Admittedly, drawing parallels between clinical and non-clinical samples can be problematic. However, our primary aim was not to evaluate models of social phobia alone, but to investigate the processes responsible for social anxiety found across many disorders. Nonetheless, the FNE scores for our high FNE group $(M=26.8)$ are comparable to, if not higher than, those reported by persons with social phobia in other studies (Rapee \& Lim, 1992; Woody \& Rodriguez, 2000; $M=22.9$ and 21.3 respectively), suggesting that similar results would be returned by a clinical sample (unless something other than FNE is responsible). In light of the moderate correlation between social anxiety and depression (Clark \& Watson, 1990), and parallel findings in depression research (Kuiper \& Derry, 1982), it is feasible that our results are a function of dysphoria rather than fear of negative evaluation. The higher depression scores reported by high FNE speakers in the present study are consistent with this explanation. Further research is necessary to determine the differential contribution of FNE and depression.

Clearly illusions of self-efficacy are not always adaptive; effective learning requires accurate feedback. Moreover, in certain circumstances being pessimistic may be adaptive. For instance, underestimating one's performance on an exam encourages the examinee to prepare for an undesired outcome (Sweeny, Carroll, \& Shepperd, 2006). However, unlike exam marks, ambiguity pervades language, much of which passes us by (i.e., it is rarely corrected). 
This, coupled with the importance of interpersonal communication to everyday functioning, promotes overestimation. In short, overestimating one's communication effectiveness is adaptive and accurate estimation is associated with dysfunction. 


\section{Acknowledgements}

This research was supported by a University of Western Australia Grant awarded to the first and second author. We thank Simon Garrod, Colin MacLeod and three anonymous reviewers for their helpful comments. 


\section{References}

Alden, L. E., \& WaLlaCe, S. T. (1995). Social Phobia and Social Appraisal in Successful and Unsuccessful Social Interactions. Behaviour Research \& Therapy, 33, 497-505.

Allbritton, D. W., McKoon, G., \& RAtcliff, R. (1996). Reliability of prosodic cues for resolving syntactic ambiguity. Journal of Experimental Psychology-Learning Memory \& Cognition, 22, 714-735.

ALLOY, L. B., \& ABRAMSON, L. Y. (1979). Judgment of contingency in depressed and non-depressed students: Sadder but wiser? Journal of Experimental Psychology: General, 108, 441-485.

Altmann, G. T. M. (1998). Ambiguity in sentence processing. Trends in Cognitive Sciences, 2, 146-152.

AmERICAN PsychiatRiC Association. (2000). Diagnostic and statistical manual of mental disorders (4th ed., text revised). Washington DC.

Amin, N., FOA, E. B., \& COLES, M. E. (1998). Negative interpretation bias in social phobia. Behaviour Research \& Therapy, 36, 945-957.

BanduRA, A. (1989). Human Agency in Social Cognitive Theory. American Psychologist, 44, 1175-1184.

ClARK, D. M., \& Wells, A. (1995). A cognitive model of social phobia. In R. G. Heimberg, M. R. Liebowitz, D. A. Hope \& F. R. Schneier (Eds.), Social phobia: Diagnosis, assessment, and treatment (pp. 69-93). New York: The Guilford Press. 
ClARK, L. A., \& WATSON, D. (1990). Theoretical and empirical issues in differentiating depression from anxiety. In J. Becker \& A. Kleinman (Eds.), Advances in mood disorders, Vol. 1. Psychological aspects of depression: Erlbaum, Hillsdale, N.J.

Constans, J. I., Penn, D. L., IhEn, G. H., \& Hope, D. A. (1999). Interpretive biases for ambiguous stimuli in social anxiety. Behaviour Research \& Therapy, 37, 643651.

HiRsch, C., \& MATHEWS, A. (1997). Interpretative inferences when reading about emotional events. Behaviour Research \& Therapy, 35, 1123-1132.

Hirsch, C. R., \& ClARK, D. M. (2004). Information-processing bias in social phobia. Clinical Psychology Review, 24, 799-825.

HiRsch, C. R., \& MATHEWS, A. (2000). Impaired positive inferential bias in social phobia. Journal of Abnormal Psychology, 109, 705-712.

KEYSAR, B., \& HENLY, A. S. (2002). Speakers' overestimation of their effectiveness. Psychological Science, 13, 207-212.

Kuiper, N. A., \& Derry, P. A. (1982). Depressed and Non-Depressed Content SelfReference in Mild Depressives. Journal of Personality, 50, 67-80.

LoviBond, P. F., \& LoviBOnd, S. H. (1995). The Structure of Negative Emotional States - Comparison of the Depression Anxiety Stress Scales (Dass) with the Beck Depression and Anxiety Inventories. Behaviour Research \& Therapy, 33, 335343.

Macmillan, N. A., \& Creelman, C. D. (1991). Detection Theory: A User's Guide. Cambridge: Cambridge University Press. 
Murphy, R., Hirsch, C. R., Mathews, A., Smith, K., \& Clark, D. M. (2007).

Facilitating a benign interpretation bias in a high socially anxious population. Behaviour Research \& Therapy, 45, 1517-1529.

Price, P. J., Ostendorf, M., Shattuckhufnagel, S., \& Fong, C. (1991). The Use of Prosody in Syntactic Disambiguation. Journal of the Acoustical Society of America, 90, 2956-2970.

RAPEE, R. M., \& HeIMBERG, R. G. (1997). A cognitive-behavioral model of anxiety in social phobia. Behaviour Research \& Therapy, 35, 741-756.

RAPEE, R. M., \& LIM, L. (1992). Discrepancy between Self and Observer Ratings of Performance in Social Phobics. Journal of Abnormal Psychology, 101, 728-731.

SAVITSKY, K., \& GILOVICH, T. (2003). The illusion of transparency and the alleviation of speech anxiety. Journal of Experimental Social Psychology, 39, 618-625.

SCHOBER, M. F., \& CONRAD, F. G. (1997). Does conversational interviewing reduce survey measurement error? Public Opinion Quarterly, 61, 576-602.

SNOdGRASs, J. G., \& CoRwIN, J. (1988). Pragmatics of Measuring Recognition Memory Applications to Dementia and Amnesia. Journal of Experimental PsychologyGeneral, 117, 34-50.

Sweeny, K., Carroll, P. J., \& SHEPPERD, J. A. (2006). Is Optimism Always Best?: Future Outlooks and Preparedness. Current Directions in Psychological Science, 15, 302-306.

TAYLOR, S. E., \& BROWN, J. D. (1988). Illusion and Well-Being: A Social Psychological Perspective on Mental Health. Psychological Bulletin, 103, 193-210. 
WATSON, D., \& FRIEND, R. (1969). Measurement of social-evaluative anxiety. Journal of Consulting \& Clinical Psychology, 33, 448-457.

Wilson, E. J., MAcLeOd, C., MAthews, A., \& Rutherford, E. M. (2006). The causal role of interpretive bias in anxiety reactivity. Journal of Abnormal Psychology, 115, 103-111.

WOODY, S. R., \& RODRIGUEZ, B. F. (2000). Self-focused attention and social anxiety in social phobics and normal controls. Cognitive Therapy \& Research, 24, 473-488. 
Table 1. The scenarios and forced choice response associated with a syntactically ambiguous test item.

Scenario $(A)$

Allan and his twin sister Sara both love to paint. Even though their styles are almost indistinguishable, their mother claims she can always tell which of them painted a picture. One day after school Allan and Sara decided to test her. They each painted a new picture. They hung one in the living room and one in the kitchen. Their mother knew immediately which was which. Sara painted the picture in the living room.

\section{Which picture did Allan paint?}

Scenario (B)

Sara was furious when she found the mess her son Allan had made in the kitchen. There were drops of paint spattered all over the floor, his paintbrushes were soaking in the kitchen sink, and he'd left his easel standing in the middle of the kitchen. But when she saw the beautiful picture Allan had painted, she was too proud to be angry. Sara hung the picture in the living room.

\section{Where did Allan paint the picture?}

Test Statement

Allan painted the picture in the kitchen. 
Disambiguating Scenarios (forced choice)

(A) The picture that is in the kitchen was painted by Allan.

(B) The picture was painted by Allan in the kitchen. 


\section{Figure Captions}

Figure 1. Scatterplot of Low and High FNE speakers' mean perceived and actual ability (\%) to convey the intended message.

Figure 2. Mean perceived and actual ability (\%) of Low and High FNE speakers' to convey the intended syntactically and lexically ambiguous message to the listener. Error bars indicate the standard error of the mean. 


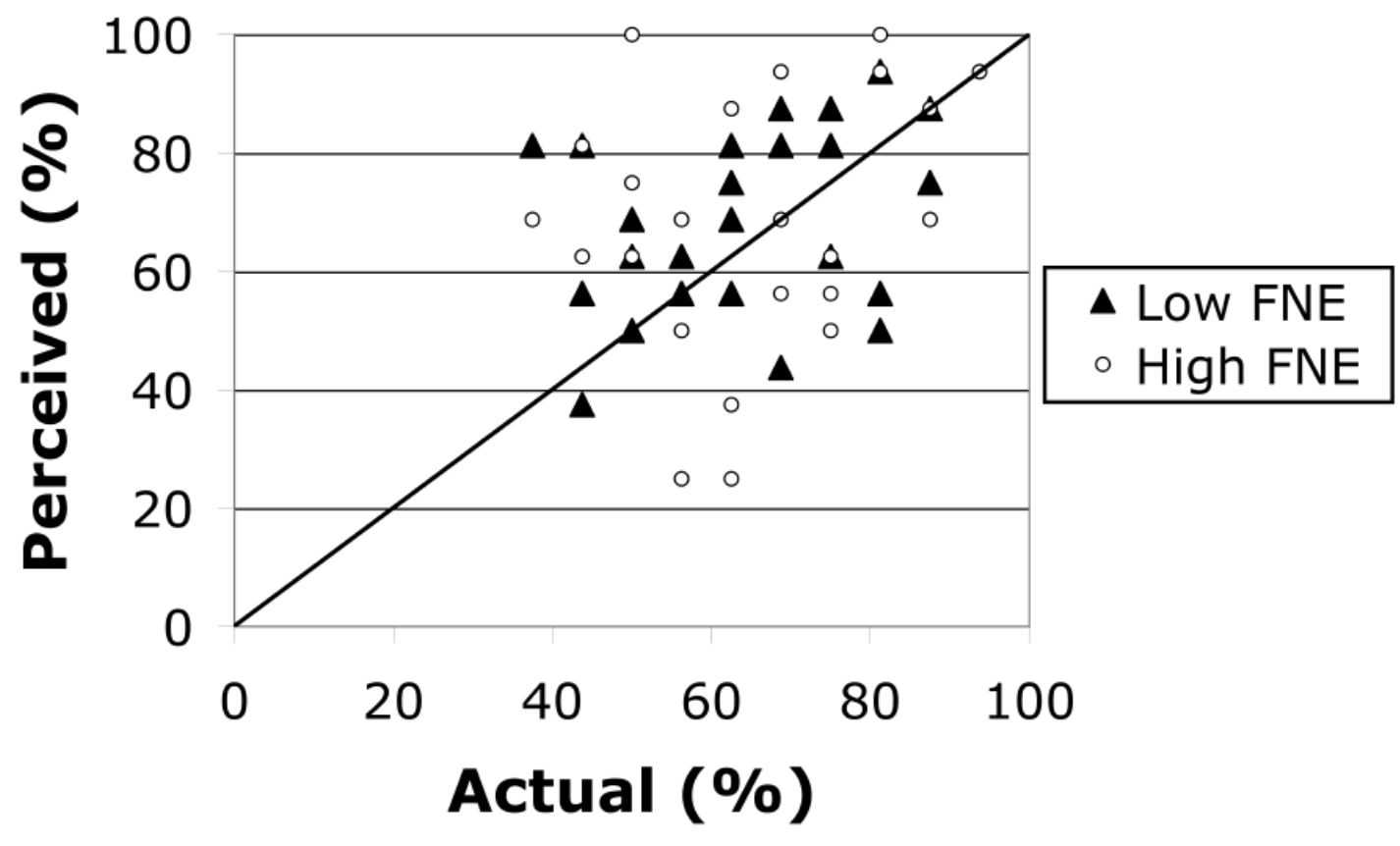




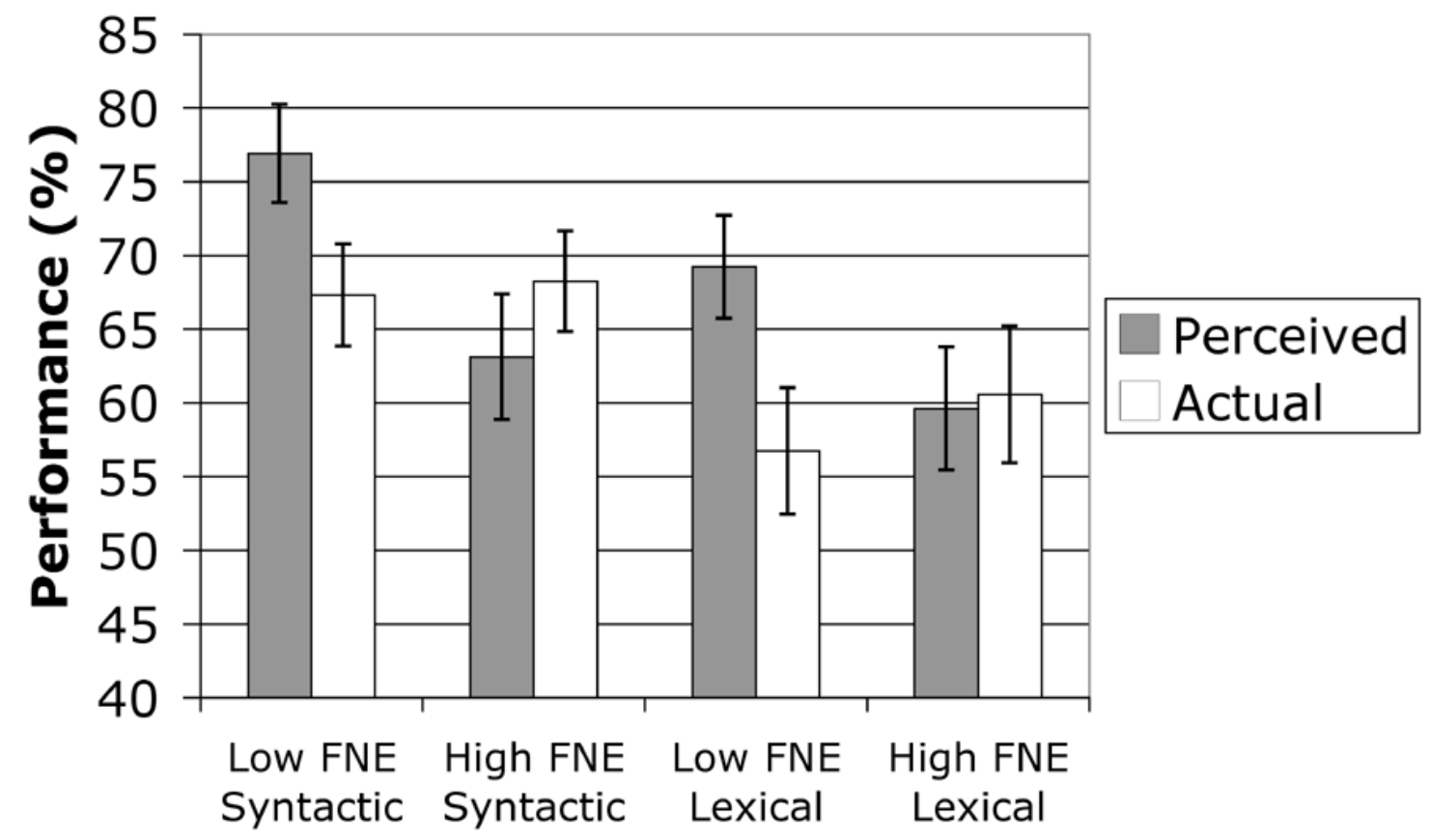


Interpersonal Communication R375B 28

\footnotetext{
${ }^{1}$ Seven participants returned incomplete DASS questionnaires and were therefore excluded from the analysis.
} 